\title{
Optimal Sizing of Decentralized Photovoltaic Generation and Energy Storage Units for Malaysia Residential Household Using Iterative Method
}

\author{
Hasimah Abdul Rahman and Nur Dalilah Nordin \\ Centre of Electrical Energy Systems, Institute of Future Energy, Universiti Teknologi Malaysia, Johor, Malaysia \\ Faculty of Electrical Engineering, Universiti Teknologi Malaysia, Johor, Malaysia
}

\begin{abstract}
World's fuel sources are decreasing, and global warming phenomena cause the necessity of urgent search for alternative energy sources. Photovoltaic generating system has a high potential, since it is clean, environmental friendly and secure energy sources. This paper presents an optimal sizing of decentralized photovoltaic system and electrical energy storage for a residential household using iterative method. The cost of energy, payback period, degree of autonomy and degree of own-consumption are defined as optimization parameters. A case study is conducted by employing Kuala Lumpur meteorological data, typical load profile from rural area in Malaysia, decentralized photovoltaic generation unit and electrical storage and it is analyzed in hourly basis. An iterative method is used with photovoltaic array variable from $0.1 \mathrm{~kW}$ to $4.0 \mathrm{~kW}$ and storage system variable from $50 \mathrm{Ah}$ to $400 \mathrm{Ah}$ was performed to determine the optimal design for the proposed system.
\end{abstract}

\section{Introduction}

World's electricity production is severely depending on coal, oil and natural gas as energy supply. However, fuel sources are decreasing, and global warming phenomena cause the necessity of urgent search for alternative energy sources. The use of renewable energy (RE) reduces the dependency on fossil fuels, and it is proven that RE has great potential and can be utilized to fulfill world energy demand [1].

Among other alternative energy available, photovoltaic (PV) system is the most promising RE in Malaysia. In the future, it is expected more installation of decentralized PV generation units combined with electrical storage in Malaysia's distribution network.

Grid tied decentralized PV generation system has numbers of advantages; modularity system, reduce dependency on conventional energy supply, environmental friendly [2] and the excess energy can be sold to utility [3], which entitled for bill reduction. Even though its potentials are proven, the coincidence of local load requirement with PV generation needs to be studied.

This paper introduces the new power management for interaction between electrical household demand, decentralized PV generation and electrical storage unit. This paper identifies the optimum configuration for PV array and storage capacity required to supply a specific load demand over a year. The optimization of system's parameters were performed under criteria of favoured cost of energy (COE), payback period (PP), degree of autonomy (DA) and degree of own consumption (DO).

\section{System configurations}

Figure 1 shows a schematic diagram for the proposed system. Referring to the figure, PV generator is used as a decentralized power source operating in grid parallel operation mode with public network. Electrical storage unit acts as the main backup power supply. Excess energy from PV plant can be sold to utility, and utility also act as backup energy when electrical storage reaches maximum depth of discharge (DOD)

The residential loads considered in the case study are only resistive loads. Figure 2 shows a typical hourly load profile for a residential house in Malaysia [4], [5] with the total daily load demand of $2.215 \mathrm{kWh}$. It is assumed that the energy requirement remains the same in each day for a year period.

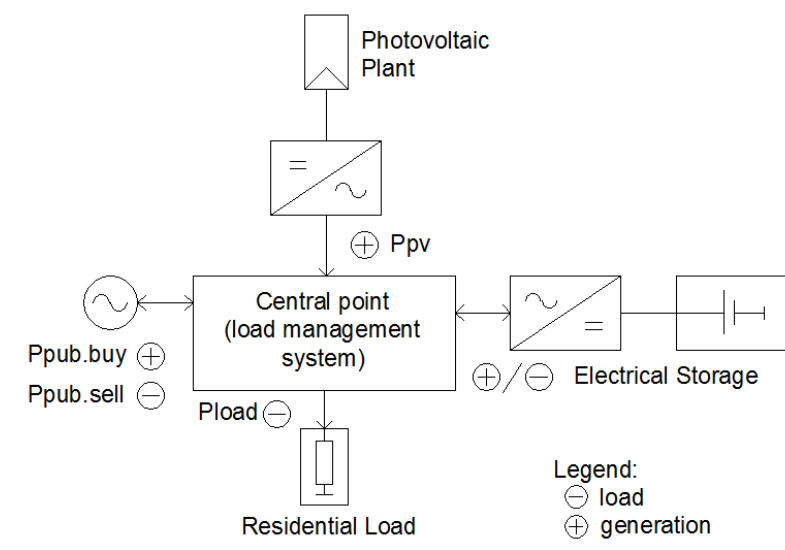

Figure 1. System configurations for a residential load in grid parallel operation mode with PV array, electrical storage and utility. 


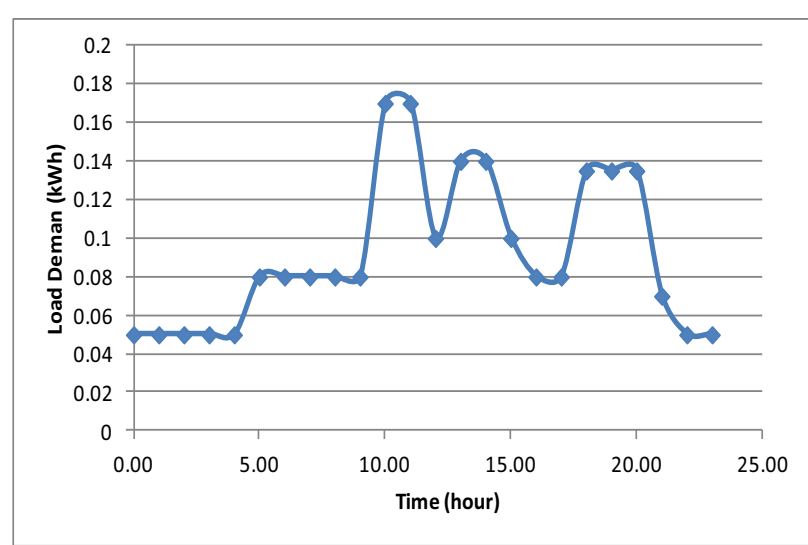

Figure 2. Hourly load profile [4], [5].

\section{System design}

In this paper, the proposed power management strategies algorithm is summarized in Figure 3. The simulation is performed by iterating the PV array variable $(0.1 \mathrm{~kW}$ $4.0 \mathrm{~kW})$ and also the storage system variable (50Ah $400 \mathrm{Ah}$ ). The priority of the management strategies is to optimize all PV energy output to supply demand. When PV output is higher than load demand, it is used to charge the battery and sell the surplus power to public network. However, when PV energy generation is not enough to supply the household load, battery will be discharge. If battery reaches lowest DOD, the additional energy for the load is supply or bought from utility.

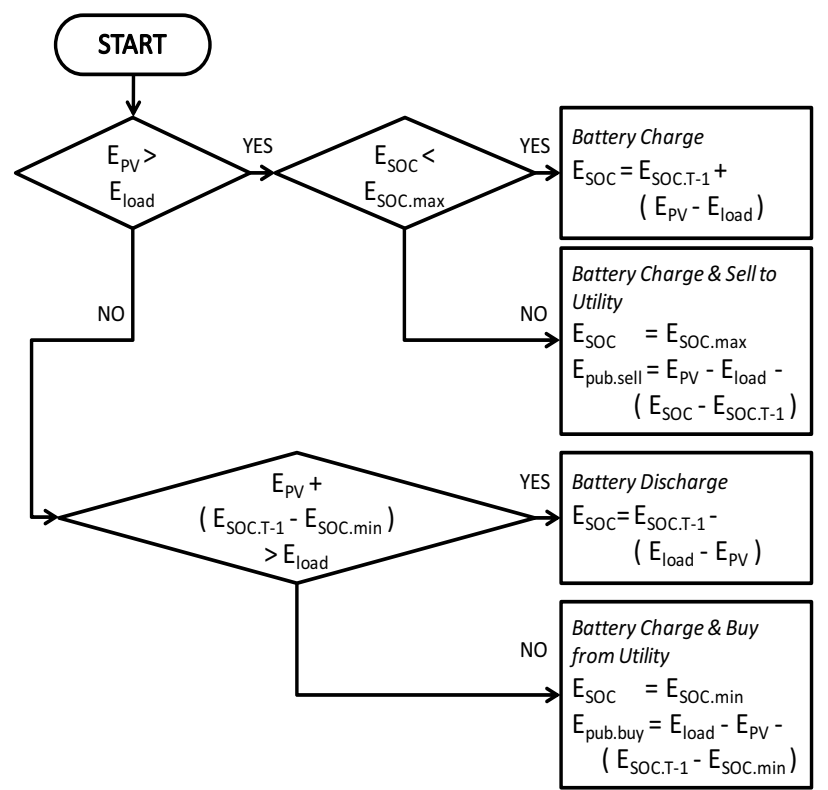

Figure 3. Power management strategies algorithm.

\subsection{PV array modeling}

PV output size must able to fulfill load demand with extra energy to cover system losses. In the analysis, Kuala Lumpur's hourly climate data is used. The hourly energy generated by $\mathrm{PV}$ array, $E_{p v}$ is calculated using Equation (1) [3], [6]. PSH is peak sun hour over the period of interest (one hour), $P_{m p \_s t c}$ is PV's maximum power output in standard test condition, $S T C, N_{p v}$ is number of PV module in the array, $\eta_{\text {temp }}$ is temperature de-rating factor, $\eta_{\text {wire }}$ is cable efficiency, $\eta_{i n v}$ is inverter efficiency, $\eta_{m m}$ is module mismatch, and $\eta_{\text {dirt }}$ is dirt derating factor.

$$
\begin{aligned}
& E_{p v}(t)=\operatorname{PSH}(t) * P_{m p_{-} s t c} * N_{p v} * \eta_{\text {temp }} * \eta_{\text {wire }} \\
& * \eta_{\text {inv }} * \eta_{m m} * \eta_{\text {dirt }}
\end{aligned}
$$

\subsection{Battery modeling}

Estimation of battery state of charge (SOC), $E_{b a t}$ analysis is shown as Equation (2) [4], [7] (charging/discharging and self discharge efficiency is ignored). $I_{b a t}$ is battery capacity in $\mathrm{Ah}$, and $V_{b a t}$ is battery's nominal voltage. Minimum SOC, $E_{S O C . m i n}$ is $50 \%$ of its full capacity.

$$
E_{b a t}(t)=Q_{b a t}(t) * V_{b a t}
$$

\subsection{Inverter size selection}

Inverter is expected to deliver maximum $\mathrm{AC}$ load in household. Hence, inverter's power rating for battery system, $P_{i n v b a t}$ is selected using Equation (3), where $P_{\text {ACload }}$ is total power from AC load demand and 1.25 is set as oversized factor [2].

$$
P_{\text {inv_bat }}=P_{\text {ACload }} * 1.25
$$

Inverter's power rating for PV array, $P_{i n v} p v$ is selected using Equation 4:

$$
P_{i n v_{-} p v}=S F_{i n v_{-} p v} * P_{m p_{-} s t c} * N_{p v}
$$

where $S F_{i n v p v}$ is inverter-to-PV sizing factor (0.80) [2], and $N_{p v}$ is quantity of PV modules in the system.

\section{System optimization criteria}

In order to select an optimum combination, four analyses were used to determine the ideal parameters for PV plant and electrical storage unit. To find optimum configuration with the lowest investment possible, it is inevitable to use economic analysis. Therefore, Cost of Energy (COE) and Payback period (PP) is used. Meanwhile, Degree of Autonomy (DA) and Degree of own-much energy generated from PV plant are used in residential household.

\subsection{Cost of energy}

$\mathrm{COE}(\mathrm{RM} / \mathrm{kWh})$ is defined as the average cost per $\mathrm{kWh}$ of electrical energy produced by the system when a lifetime, investment cost, replacing, operation \& maintenance, and capital cost is considered [8]. Based on technical datasheet, the batteries need to be replaced for every 5 years and inverter need to be replaced every 10 years [5]. Lower COE is desirable and it is calculated by dividing producing electricity annualized life cycle cost, $L C C_{\text {lyear }}$ with $E_{P V}$ [9]. The market price for system components is summarized as in Table 1 [9], [10]. 


$$
\begin{gathered}
L C C=C_{p v}+C_{\text {controller }}+C_{\text {bat }}+C_{\text {inv }}+ \\
C_{\text {install }}+C_{\text {batrep }}+C_{\text {invrep }}+C_{\text {O\&M_25years }}-C_{\text {salvage }} \\
L C C_{1 \text { year }}=\frac{L C C}{\left[\frac{(1+i)^{N}}{i(1+i)^{N}}\right]} \\
C O E=\frac{L C C_{1 \text { year }}}{E_{P V}}
\end{gathered}
$$

\subsection{Payback period}

PP is used to determine the time it would take to recover or break even on initial investment cost and ongoing O\&M cost [11]. $E_{\text {sell }}$ is energy fed back to utility during surplus energy from PV and $E_{\text {buy }}$ is energy bought from utility during lack of PV output. Meanwhile, feed in tariff, FIT is different for each country, and for Malaysia, it is $\mathrm{RM} 1.35 / \mathrm{kWh}$ in 2015 [10]. Each energy unit bought from utility is provided by Tenaga Nasional Berhad, TNB [12]. Shorter payback period are more desirable.

\begin{tabular}{|c|c|c|c|}
\hline \multicolumn{2}{|r|}{ Component } & Unit & Price \\
\hline \multicolumn{2}{|r|}{ Module } & $\mathrm{RM} / \mathrm{Wp}$ & 5.000000 \\
\hline \multicolumn{2}{|r|}{ Battery } & $\begin{array}{l}\text { RM/Output } \\
\text { Watt Hour }\end{array}$ & 0.041667 \\
\hline \multicolumn{2}{|r|}{ Inverter } & $\begin{array}{l}\text { RM/Continuous } \\
\text { Watt }\end{array}$ & 1.000000 \\
\hline \multicolumn{2}{|r|}{$\begin{array}{l}\text { Support Structure \& } \\
\text { Installation cost }\end{array}$} & $\mathrm{RM} / \mathrm{Wp}$ & 4.000000 \\
\hline \multirow{5}{*}{ FIT } & $\begin{array}{c}\begin{array}{c}\text { Basic FiT rates up } \\
\text { to and including } \\
4 \mathrm{~kW}\end{array} \\
\end{array}$ & $\mathrm{RM} / \mathrm{Wh}$ & 0.000917 \\
\hline & $\begin{array}{l}\text { Use as installation } \\
\text { in buildings or } \\
\text { building structures }\end{array}$ & $\mathrm{RM} / \mathrm{Wh}$ & 0.000172 \\
\hline & $\begin{array}{l}\text { Use as building } \\
\text { materials }\end{array}$ & $\mathrm{RM} / \mathrm{Wh}$ & 0.000166 \\
\hline & $\begin{array}{c}\text { Use of locally } \\
\text { manufactured or } \\
\text { assembled solar PV } \\
\text { modules }\end{array}$ & $\mathrm{RM} / \mathrm{Wh}$ & 0.000050 \\
\hline & $\begin{array}{l}\text { Use of locally } \\
\text { manufactured or } \\
\text { assembled solar } \\
\text { inverters }\end{array}$ & $\mathrm{RM} / \mathrm{Wh}$ & 0.000050 \\
\hline \multicolumn{2}{|c|}{ TNB Bill pricing tariff } & $\mathrm{RM} / \mathrm{Wh}$ & 0.000218 \\
\hline
\end{tabular}

$$
P P=\frac{L C C}{\left(\sum_{365}^{T} E_{\text {sell }} * F I T\right)-\left(\sum_{365}^{T} E_{b u y} * T N B\right)}
$$

Table 1. Components' pricing.

\subsection{Degree of autonomy}

DA shows how much energy provided from decentralized PV generator and directly used in residential household compared to the whole energy demand. It is calculated using Equation (9) [13]:

$$
D A=\frac{\sum_{365}^{T} E_{p v}-\sum_{365}^{T} E_{\text {sell }}}{\sum_{365}^{T} E_{p v}-\sum_{365}^{T} E_{\text {sell }}+\sum_{365}^{T} E_{b u y}-E_{\text {bat_start }}+E_{\text {bat_end }}}
$$

where $E_{\text {bat_start }}$ is initial battery's energy and $E_{\text {bat_end }}$ is battery's energy at the end of the period. Higher DA is desirable for optimum configuration.

\subsection{Degree of own-consumption}

Meanwhile, DO shows how much energy is provided from decentralized PV plant that is directly used by the residential household compared to the provided power by PV generator. It is calculated as Equation 10 [13]. However, contrast with DA, optimum design tends to have lower DO.

$$
D O=\frac{\sum_{365}^{T} E_{p v}-\sum_{365}^{T} E_{\text {sell }}}{\sum_{365}^{T} E_{p v}-E_{b a t_{\text {_start }}}+E_{\text {bat_end }}}
$$

\section{Results and discussion}

Figure 4, 5, 6 and 7 show the analyses results based on the optimization criteria as stated in equations 7, 8, 9 and 10. Referring to Figure 4, it shows the results from COE analysis as the optimization criteria. It can be seen that when battery capacity ranged from $50 \mathrm{Ah}$ to $100 \mathrm{Ah}$ is paired with PV capacity from $3 \mathrm{~kW}$ to $4 \mathrm{~kW}$, the system obtained the lowest COE of RM $0.57 / \mathrm{kWh}$.

Figure 5 is obtained after payback period analysis was performed; it is observed that for all combination of battery capacity at the PV ranged from $0.3 \mathrm{~kW}$ to $0.9 \mathrm{~kW}$ gives the payback period more than 20 years. Hence, it can be concluded that any configuration within the specified range of PV capacity is not feasible. This is due to insufficient PV output, which causes the total benefit obtained from selling energy to utility is inadequate to break-even on LCC system. However, for all pairs of battery capacity at the PV ranged from $3.45 \mathrm{~kW}$ to $4 \mathrm{~kW}$ gives PP lower than 8 years.

Hence, the lowest PP and DO values obtained are 7.333 years and $0.1436 \mathrm{p} . \mathrm{u}$ respectively at the combination of $4 \mathrm{~kW}$ PV array and 50Ah battery capacity. Meanwhile, the highest DA obtained using the configuration of $4 \mathrm{~kW} \mathrm{PV}$ capacity and $100 \mathrm{Ah}$ is 0.9998p.u. 


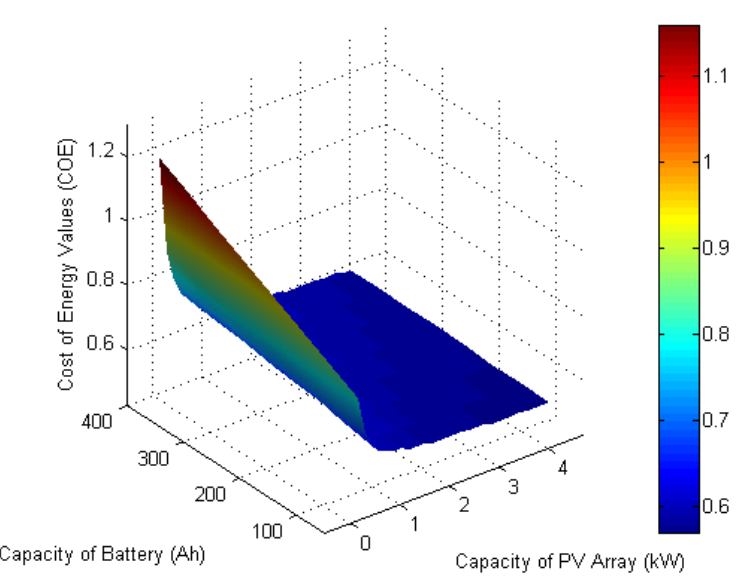

Figure 4. Results of COE analysis.

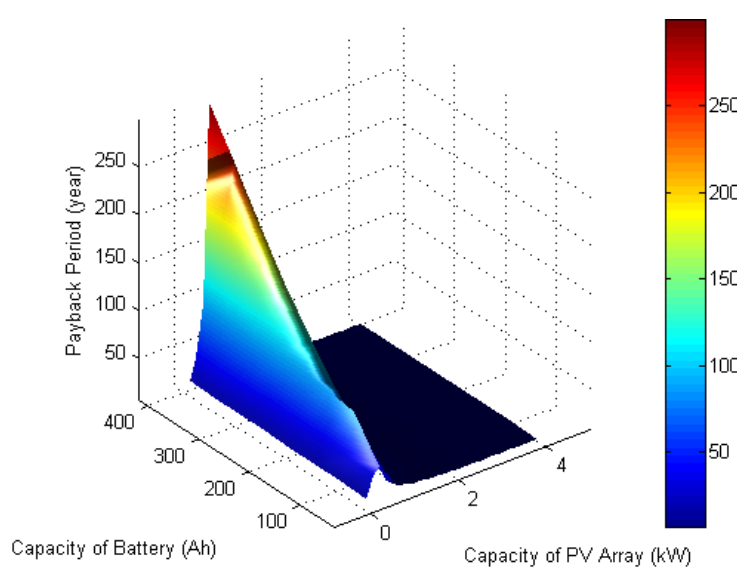

Figure 5. Results of PP analysis.

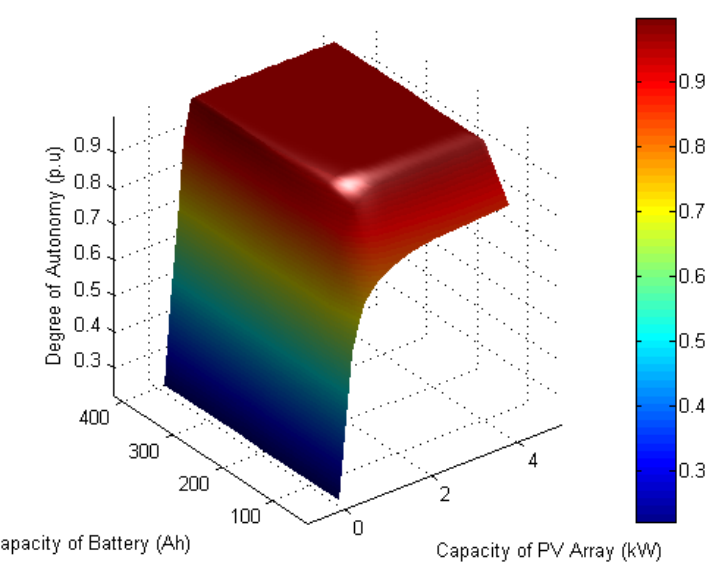

Figure 6. Results of DA analysis.

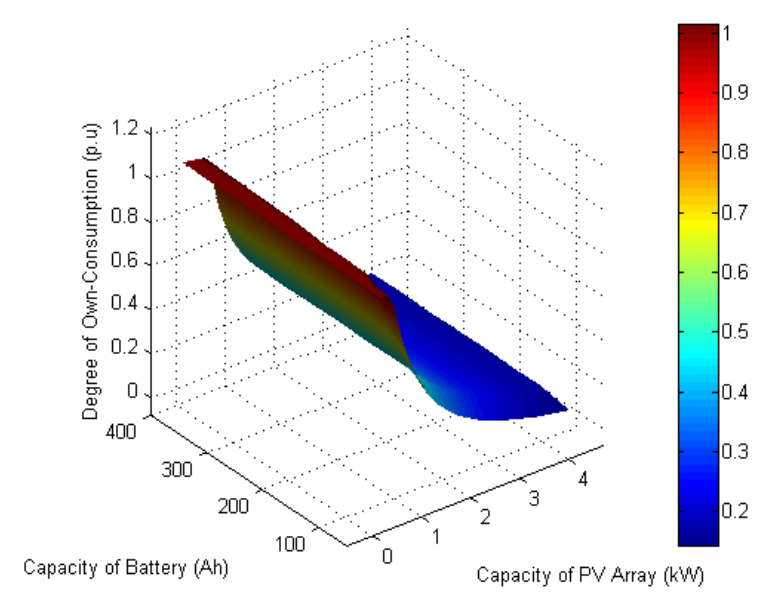

Figure 7. Results of DO analysis.

\section{Conclusions}

The optimal sizing of decentralized photovoltaic generation and energy storage units for Malaysia residential household has been presented. From the results obtained, the most favorable design is either a system of PV capacity $4 \mathrm{~kW}$ and $50 \mathrm{Ah}$ or $100 \mathrm{Ah}$ battery capacity, which is obtained from the lowest DO or the highest DA value. However, based on the observation, it is wiser to select the best combination parameters using DA analysis. It is because DA indicates which design has high degree of energy independence from local utility with lowest COE and low PP. The selected parameter pair is able to use most energy from PV generator directly in residential household, with low energy need to be bought from utility and has small changes between initial and ending battery's capacity.

This has proven that it is possible to effectively use RE sources and storage that allows the system to be independent from utility, and gain profit from solar FIT.

\section{Acknowledgement}

Authors wish to acknowledge the supports for this paper received from Malaysian Ministry of Higher Education (MOHE) and Universiti Teknologi Malaysia through Research University Grant (RUG; Vote no: Q.J13000.2509.07H54). This research is also partially supported by MOSTI (Vote no: RJ130000.7923.4S068).

\section{References}

1. A. Mellit, and S. A. Kalogirou, Artificial intelligence techniques for photovoltaic applications: A review. Progress in Energy and Combustion Science, 34(5): pp. 574-632 (2008)

2. S. I. Sulaiman, et al., Sizing grid-connected photovoltaic system using genetic algorithm. Industrial Electronics and Applications (ISIEA), 2011 IEEE Symposium on IEEE (2011)

3. S. I. Sulaiman, et al., An intelligent method for sizing optimization in grid-connected photovoltaic system. Solar Energy, 86(7): pp. 2067-2082 (2012)

4. W. Shen, Optimally sizing of solar array and battery in a standalone photovoltaic system in Malaysia. Renewable Energy, 34(1): pp. 348-352 (2009)

5. N.D. Nordin, and H.A. Rahman. An optimization method for designing stand alone photovoltaic system using iterative method. in Smart Energy Grid Engineering (SEGE), 2015 IEEE International Conference (2015)

6. R.Dufo-López, J.M. Lujano-Rojas, and J.L. BernalAgustín, Comparison of different lead-acid battery lifetime prediction models for use in simulation of stand-alone photovoltaic systems. Applied Energy, 115: pp. 242-253 (2014)

7. J. Li, W. Wei, and J. Xiang, A Simple Sizing Algorithm for Stand-Alone PV/Wind/Battery Hybrid Microgrids. Energies, 5(12): pp. 5307-5323 (2012) 
8. S. Kamel, and C. Dahl, The economics of hybrid power systems for sustainable desert agriculture in Egypt. Energy, 30(8): pp. 1271-1281 (2005)

9. J. Abdulateef, et al., Economic analysis of a standalone PV system to electrify a residential home in Malaysia. 10th IASME/WSEAS International Conference on Heat Transfer, Thermal Engineering and Environment (HTE'12) (2012)

10. FIT Malaysia. Available from: http://seda.gov.my/.

11. Simple Photovoltaic Economic Calculations. Available http://www1.eere.energy.gov/solar/pdfs/simple_pv_e conomic_calculations_tn.pdf

12. TNB - tariff. ${ }^{-}$Available from: https://www.tnb.com.my/residential/pricing-tariffs/

13. T. Wieland, et al., Optimal sizing of electric and thermal energy storage units for residential households with decentralized generation units in the low voltage grid. Electric Power Quality and Supply Reliability Conference (PQ), IEEE (2014) 